\title{
Eine merkwürdige Monstruosität an Carineta formosa Germ.
}

Von C. Schrottky in Villa Encarnacion, Paraguay.

(Mit 2 Figuren im Texte.)

Das mir vorliegende Stück, das abends bei Licht in Villa Encarnacion, Paraguay, gefangen wurde, weist eigentümliche Mißbildungen einiger wesentlicher Organe auf. Das rechte Vorderbein nämlich, jedenfalls durch eine mechanische Einwirkung im Nymphenstadium veranlaßt, hat seine natürliche Lage mit einer höchst seltsamen vertauscht. Es entspringt aus der Stirn. Dadurch ist nun die ganze rechte Prothoraxseite, sowie der Kopf stark verbildet. Das Bein, dessen Femur, Tibie und Tarsus vollkommen normal sind, scheint trotz seiner sonderbaren Stellung doch ganz gut funktioniert zu haben, obgleich das leider an dem mir bereits nicht mehr frisch überbrachten Stücke, ohne es zu zerstören, nicht mehr festzustellen war.

Am Prosternum ist dort, wo sich die Coxa des rechten Vorderbeines befinden sollte, nur ein vollständig leerer Raum, ohne daß daselbst etwas von einer Mißbildung zu bemerken wäre. Das Pronotum ist in seiner linken Hälfte normal, die rechte dagegen weist beträchtliche pathologische Veränderungen auf. Zunächst ist sie um etwa einen halben Millimeter schmäler als die linke, und zwar hat sich eine Chitinplatte durch den vermutlich von der Seite her wirkenden Druck abgespalten und dachziegelartig über den danebenliegenden Teil geschoben. Von der Mitte aus reicht die normale Beschaffenheit des Pronotums bis an etwa ein Viertel des gelben Fleckes (rechts) hin, dann folgt die im Basalteil gelbe, im Apicalteil schwarze oben erwähnte Chitinplatte, deren Spitze fast den hinteren Rand des Pronotums erreicht, darauf die schwarze Flügelschuppe.

Während auf der normalen linken Seite Kopf und Thorax deutlich geschieden sind, gehen sie rechts durch eine Art scheinbaren Halses ineinander über. Dieser Hals wird dadurch gebildet, daß das rechte Facettenauge um etwa $1.5 \mathrm{~mm}$ vom Vorderrande des Pronotums abgedrängt ist; dadurch entsteht eine tiefe Furche, die aussieht als ob das aus der Stirn entspringende Bein taschenmesserartig in sie hineingeklappt werden könnte. Trotz der veränderten Lage ist das rechte Facettenauge ebenso groß geblieben fals das

Wiener Entomologische Zeitung, XXV. Jahrg., Heft VIII und IX (15. August 1906). 
linke, jedoch ist sein äuferer Rand mit Haaren besetzt, was bei dem linken, da es hinten an den Prothorax stoßt, nicht der Fall ist. Die Ocellen stehen merkwürdigerweise weit mehr nach rechts

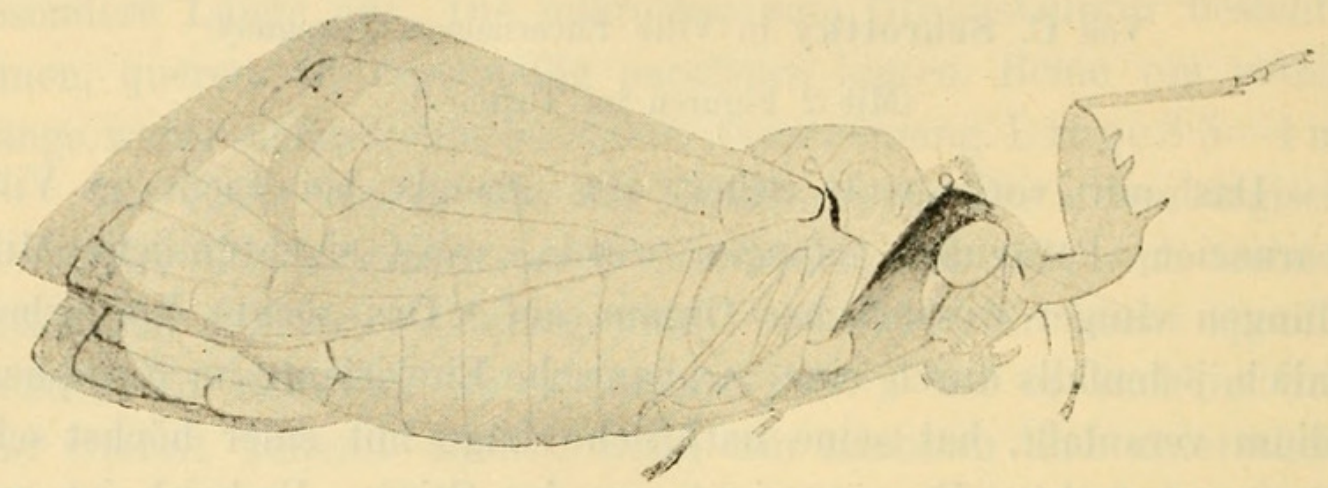

Fig. 1.

zu, als man bei den allgemein nach links gedrängten übrigen Teilen erwarten sollte; der linke steht etwa vor der Mitte des Pronotums

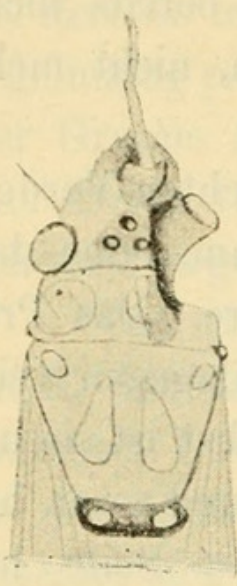

Fig. 2. (genau zwischen den beiden gelben Flecken), der rechte hart an der vorerwähnten Furche; der vordere steht dem linken ein wenig näher als dem rechten.

Fig. 1 stellt das Tier von der Seite dar, ein wenig schräg von unten gesehen, um das ganze ausgestreckte Vorderbein in eine Ebene zu bekommen; bis auf die veränderte Lage des Beines sind hier die Mißbildungen nicht zu bemerken. An Fig. 2, die Kopf und Thorax von oben gesehen darstellt, lassen sich die verbildeten Teile gut erkennen, dagegen ließ sich die Lage des Beines nicht besonders gut veranschaulichen.

Über die Ursache dieser Monstruosität läßt sich nur die Vermutung aussprechen, daß das Tier im Nymphenstadium durch einen Druck oder Stof verletzt wurde und die noch weichen Teile, die durch diese äußere Einwirkung verschoben waren, ohneweiters verheilten. Wie gesagt, schien das Bein trotz seiner ungehörigen Lage wie das normale funktioniert zu haben. In diesem Falle wären aus der Lage der diesbezüglichen Muskeln und Nerven weitere und sicherere Schlüsse auf die vermutlichen Ursachen möglich gewesen.

Villa Encarnación, 1. Jänner 1906. 


\section{$2 \mathrm{BHL}$ Biodiversity Heritage Library}

Schrottky, Curt. 1906. "Eine merkwürdige Monstruosität an Carineta formosa GERM." Wiener entomologische Zeitung 25, 261-262.

https://doi.org/10.5962/bhl.part.5400.

View This Item Online: $\underline{\text { https://www.biodiversitylibrary.org/item/43835 }}$

DOI: https://doi.org/10.5962/bhl.part.5400

Permalink: https://www.biodiversitylibrary.org/partpdf/5400

\section{Holding Institution}

Smithsonian Libraries

\section{Sponsored by}

Smithsonian

\section{Copyright \& Reuse}

Copyright Status: NOT_IN_COPYRIGHT

This document was created from content at the Biodiversity Heritage Library, the world's largest open access digital library for biodiversity literature and archives. Visit BHL at https://www.biodiversitylibrary.org. 